\title{
HUBUNGAN ANEMIA DEFISIENSI BESI PADA IBU HAMIL DENGAN KEJADIAN ABORTUS DI RUANGAN KASUARI RUMAH SAKIT UMUM ANUTAPURA PALU
}

\author{
Lisda Widianti \\ Jurusan Kebidanan, Poltekkes Kemenkes Palu \\ Email: lisda.santo@gmail.com
}

\begin{abstract}
Relation of Iron Deficiency Anemia in Pregnant Women with Abortion in Kasuari Anutapura Public Hospital, Palu. Factors that can lead to abortion were the factor of fetal, maternal factor, father factor, factors of infection and nutritional factors. Maternal factor that commonly happen were iron deficiency anemia. This study was to determine a relation of iron deficiency anemia in pregnant women with abortion. This study was conducted in Kasuari Anutapura Public Hospital, Palu, Central Sulawesi. This study was cross sectional design. Samples were taken with consecutive sampling technique, as many as 46 people. Data were analyzed with chi square test with p-value of 0,05. Results showed that there was a relationship between iron deficiency anemia in pregnant women with abortion, in Kasuari Anutapura Public Hospital, Palu.
\end{abstract}

Keywords: Abortus, Anemia, Pregnancy

\begin{abstract}
Abstrak: Hubungan Anemia Defisiensi Besi pada Ibu Hamil dengan Kejadian Abortus di Ruangan Kasuari Rumah Sakit Umum Anutapura Palu. Faktor-faktor yang dapat menyebabkan abortus diantaranya adalah faktor janin, faktor ibu, faktor bapak, faktor infeksi dan faktor gizi. Penyebab dari faktor ibu yang sering terjadi adalah anemia defisiensi zat besi. Tujuan penelitian ini adalah diketahuinya hubungan anemia defisiensi besi pada ibu hamil dengan kejadian Abortus. Penelitian ini dilaksanakan di Rumah Sakit Umum Anutapura Palu Sulawesi Tengah. Penelitian ini menggunakan desaincross sectional study. Sampel diambil sebanyak 46 orang dengan teknik consecutive sampling. Data dianalisis dengan uji chi square dengan nilai $p$ 0,05 . Hasil penelitian menunjukkan bahwa ada hubungan anemia defisiensi besi pada ibu hamil dengan kejadian abortus di ruangan nifas Rumah Sakit Umum Anutapura Palu.
\end{abstract}

Kata kunci: Abortus, Anemia, Kehamilan

Kehamilan merupakan masa kehidupan yang penting, pada masa ini ibu harus mempersiapkan diri sebaik-baiknya untuk menyambut kelahiran bayinya. Salah satu faktor yang berpengaruh terhadap kesehatan ibu selama kehamilan ibu perlu memperhatikan makanan sehari-hari agar terpenuhi zat gizi yang dibutuhkan selama kehamilan. Empat masalah gizi utama di Indonesia yang belum teratasi, salah satunya adalah anemia. Anemia masih merupakan masalah pada wanita Indonesia sebagai akibat kekurangan zat besi dan asam folat dalam tubuh serta faktor lain seperti infeksi, cacingan dan penyakit kronis (Manuaba, 2013).

Anemia adalah kondisi ibu dengan kadar haemoglobin $(\mathrm{Hb})$ dalam darahnya kurang dari $12 \mathrm{~g} / \mathrm{dl}$. Anemia dalam kehamilan adalah kondisi ibu dengan kadar haemoglobin dibawah $11 \mathrm{~g} / \mathrm{dl}$ pada trimester I dan III atau kadar <10,5 g/dl pada trimester II. Anemia dalam kehamilan yang disebabkan karena kekurangan zat besi, jenis pengobatannya relatif mudah, bahkan murah.
Dampak anemia pada kehamilan bervariasi dari keluhan yang sangat ringan hingga terjadinya gangguan kelangsungan kehamilan (abortus, partus imatur/prematur), gangguan proses persalinan (perdarahan), gangguan pada masa nifas (daya tahan terhadap infeksi kurang dan produksi ASI rendah), dan gangguan pada janin (abortus, dismaturitas, BBLR, kematian perinatal dan lain-lain) (Soeprono, 2013).

Abortus didefinisikan sebagai keluarnya hasil konsepsi sebelum mampu hidup diluar kandungan dengan berat badan kurang dari 1000 gram atau umur kehamilan kurang dari 28 minggu (Manuaba, 2012). Beberapa faktor yang dapat menyebabkan abortus diantaranya adalah faktor janin, faktor ibu, faktor bapak, faktor infeksi dan faktor nutrisi (Rukiyah dan Yulianti, 2010:136). Kekurangan gizi pada bumil dapat menyebabkan BBLR, terhambatnya pertumbuhan otak janin, bayi lahir dengan kurang darah (anemia), bayi mudah kena infeksi dan dapat mengakibatkan abortus. Masalah gizi yang sering 
terjadi pada ibu hamil adalah anemia defisiensi zat besi (Paath dkk, 2005).

Menurut World Health Organization (WHO) sekitar $40 \%$ kematian ibu di negara berkembang berkaitan dengan anemia dalam kehamilan. Kebanyakan anemia dalam kehamilan disebabkan oleh defisiensi besi dan perdarahan akut bahkan tidak jarang keduanyasaling berinteraksi (Prawirohardjo, 2013).WHO juga melaporkan bahwa prevalensi anemia pada kehamilan secara global 55\% dimana yang tertinggi pada trimester ketiga dibandingkan dengan trimester pertama dan kedua kehamilan. Dan juga WHO melaporkan prevalensi ibu-ibu hamil yang mengalami defisiensi besi sekitar $35-37 \%$ dan semakin meningkat seiring dengan pertambahan usia kehamilan (Soeprono, 2013).

Berdasarkan Survei Demografi dan Kesehatan Indonesia (SDKI) tahun 2012, angka kematian ibu di Indonesia masih tinggi sebesar 359 per 100.000 kelahiran hidup. Angka ini sedikit menurun jika dibandingkan dengan SDKI tahun 1991, yaitu sebesar 390 per 100.000 kelahiran hidup.angka ini sedikit menurun meskipun tidak terlalu signifikan.Lima penyebab kematian ibu terbesar adalah perdarahan, Hipertensi dalam kehamilan (HDK), infeksi, partus lama/macet dan abortus (Riskesdas, 2013).

Berdasarkan hasil survei Sub Bagian Program Kesehatan Ibu dan Anak Dinas Kesehatan Provinsi Sulawesi Tengah tahun 20142015 jumlah kasus kematian ibu mengalami peningkatan yaitu pada tahun 2014 jumlah angka kematian ibu sebanyak 107 orang, terdiri dari perdarahan 43 orang $(40,18 \%)$, hipertensi dalam kehamilan 25 orang $(23,36 \%)$, infeksi 6 orang $(5,60 \%)$, dan lain-lain 33 orang $(30,84 \%)$. Tahun 2015 jumlah kasus kematian ibu sebanyak 129 orang, terdiri dari perdarahan 46 orang $(45,65 \%)$, hipertensi dalam kehamilan 22 orang $(17,05 \%)$, infeksi 10 orang $(7,75 \%)$, gangguan sistem peredaran darah 6 orang $(4,65 \%)$, gangguan metabolik 1 orang $(0,77 \%)$, lain-lain 44 orang $(34,11 \%)$. (Dinkes Sulteng, 2015)

Berdasarkan data yang diperoleh dari Dinas Kesehatan Kota Palu laporan kasus maternal kematian ibu dari Dinas Kesehatan Kota Palu dari tahun 2014-2015 mengalami peningkatan yaitu pada tahun 2014 jumlah AKI 8 orang terdiri dari hipertensi dalam kehamilan 2 orang $(25 \%)$, dan lain-lain 6 orang $(75 \%)$.Tahun 2015 jumlah angka kematian ibu 22 orang terdiri dari perdarahan 8 orang $(36,36 \%)$, hipertensi dalam kehamilan 2 orang $(9,09 \%)$, infeksi 1 orang $(4,54 \%)$, dan lain-lain 11 orang $(50 \%)$. Tahun 2014-2015 terdapat penurunan jumlah data abortus yaitu pada tahun 2014 sebanyak 153 kejadian abortus dan tahun 2015 terdapat 149 kejadian abortus. (Dinkes Kota Palu, 2015)

Berdasarkan survei yang dilakukan peneliti pada 2 rumah sakit di Kota Palu yaitu pada Rumah Sakit Daerah Madani dan Rumah Sakit Umum Anutapura, jumlah kasus kejadian abortus pada Rumah Sakit Daerah Madani tahun 2013 terdapat 115 kasus $(13,9 \%)$ dari total kunjungan 827 kasus, pada tahun 2014 terdapat 73 kasus $(12,3 \%)$ dari total kunjungan 592 kasus dan tahun 2015 sebanyak 96 kasus $(8,21 \%)$ dari total kunjungan 1.168 kasus (RSD Madani 20132015).

Data Rumah Sakit Umum Anutapura tahun 2014 kejadian abortus 443 kasus $(12,17 \%)$, terdapat $295 \mathrm{ibu}$ yang mengalami abortus dengan kadar $\mathrm{Hb}<5 \mathrm{~g} / \mathrm{dl}$ dan 148 ibu yang mengalami abortus dengan kadar $\mathrm{Hb} 6$ gr/dl-7,9 g/dl. ( RSU Anutapura, 2014). Tahun 2015 kejadian abortus sebanyak 319 kasus $(8,98 \%)$ terdapat 200 ibu yang mengalami abortus dengan kadar $\mathrm{Hb}<5$ $\mathrm{g} / \mathrm{dl}$ dan 119 ibu yang mengalami abortus dengan kadar Hb 6 gr/dl-7,9 g/dl(RSU Anutapura, 2015). Meskipun terdapat penurunan angka kejadian abortus dengan anemia, tapi masih dianggap cukup tinggi.

\section{METODE PENELITIAN}

Penelitian ini menggunakan desain Studi Potong Lintang (Cross Sectional Study). Populasi dalam penelitian ini adalah semua ibu hamil usia kehamilan <20 minggu yang dirawat diruang nifas pada saat penelitian dilakukan. Pengambilan sampel dalam penelitian ini menggunakan teknik Consecutive Sampling, sampel yang didapatkan sejumlah 46 responden. Analisis bivariat menggunakan uji Chi Square dengan tingkat kepercayaan $95 \%$.

\section{HASIL}

\section{A. ANALISIS UNIVARIAT}

Berdasarkan hasil penelitian, didapatkan data jumlah ibu hamil yang menderita anemia 28 orang $(60,8 \%)$ dan ibu hamil yang tidak menderita anemia sejumlah 18 orang $(39,2 \%)$. Jumlah kasus abortus sebanyak 23 orang (50\%) dan untuk lebih jelasnya dapat dilihat pada tabel berikut: 
Tabel 1. Anemia Defisiensi Besi Ibu Hamil

\begin{tabular}{lcc}
\hline \multicolumn{1}{c}{ Anemia } & Frekuensi & \% \\
\hline Anemia & 28 & 60,8 \\
Tidak Anemia & 18 & 39,2 \\
\hline Jumlah & 46 & 100 \\
\hline
\end{tabular}

Tabel 2. Kejadian Abortus Pada Ibu Hamil $<20$ Minggu

\begin{tabular}{lcc}
\hline $\begin{array}{c}\text { Kejadian } \\
\text { Abortus }\end{array}$ & Frekuensi & $\%$ \\
\hline Abortus & 23 & 50 \\
Tidak Abortus & 23 & 50 \\
\hline Jumlah & 46 & 100 \\
\hline
\end{tabular}

\section{B. ANALISIS BIVARIAT}

Tabel 3. Hubungan Antara Anemia Defisiensi Besi Pada Ibu Hamil dengan Kejadian Abortus

\begin{tabular}{lcccccc}
\hline \multirow{2}{*}{$\begin{array}{c}\text { Kejadian } \\
\text { Abortus }\end{array}$} & \multicolumn{4}{c}{ Anemia } & \multicolumn{1}{c}{$\begin{array}{c}\text { Total } \\
\text { (n) }\end{array}$} & $\begin{array}{c}\boldsymbol{p} \text { - } \\
\text { value }\end{array}$ \\
\cline { 2 - 6 } & & \multicolumn{4}{c}{ Anemia } & \multicolumn{2}{c}{ Tidak } \\
& Anemia & & \\
\cline { 2 - 5 } & $\mathbf{f}$ & $\mathbf{\%}$ & $\mathbf{f}$ & $\mathbf{\%}$ & & \\
\hline Abortus & 22 & 78,6 & 1 & 5,6 & 23 & \\
\hline $\begin{array}{l}\text { Tidak } \\
\text { Abortus }\end{array}$ & 6 & 21,4 & 17 & 94,4 & 23 & 0,000 \\
\hline Jumlah & 28 & 100 & 18 & 100 & 46 & \\
\hline
\end{tabular}

\section{PEMBAHASAN}

Hasil penelitian menunjukkan ibu yang mengalami anemia sebanyak 28 responden $(60,8)$ dan yang tidak mengalami anemia sebanyak 18 responden $(39,2 \%)$. Ibu yang mengalami abortus sebanyak 23 responden $(50 \%)$ dan tidak abortus sebanyak 23 responden (50\%). Hasil ujichi squarenilai $p: 0,000$ ( $p$-value $\leq 0,05)$ artinya ada hubungan antara anemia defisiensi besi pada ibu hamil dengan kejadian abortus diruang nifas RSU Anutapura Palu.Ibu hamil yang mengalami anemia difisiensi besi sangat rentan atau beresiko untuk terjadi abortus. Hal ini disebabkan karena dalam kehamilan zat besi berperan sebagai hematopoiesis (pembentukan darah) yaitu dalam sintesa haemoglobin $(\mathrm{Hb})$. Seorang ibu yang dalam masa kehamilannya telah menderita kekurangan zat besi tidak dapat memberi cadangan zat besi kepada bayinya dalam jumlah yang cukup untuk beberapa bulan pertama.Hal inilah yang menyebabkan bahwa seorang ibu hamil yang mengalami anemia pada usia kehamilan <20 minggu dapat menyebakan abortus.
Anemia yang terjadi pada saat hamil dapat memberikan efek buruk, baik pada ibu atau pada janin yang dikandungnya. Anemia dapat mengurangi suplai oksigen pada metabolisme ibu dan janin karena dengan kurangnya kadar hemoglobin maka berkurang pula kadar oksigen dalam darah. Keadaan ini jika berlangsung lama dapat menyebabkan nekrosis pada jaringan, sehingga hasil konsepsi tidak bisa bertahan lama pada ovarium. Gejala awal yang di timbulkan terjadinya perdarahan dalam desidua basalis yang diikuti oleh nekrosis jaringan sekitarnya yang menyebabkan hasil konsepsi terlepas sebagian atau seluruhnya, sehingga bagian yang terlepas ini merupakan benda asing dalam uterus.Ini menyebabkan uterus berkontraksi untuk mengeluarkan benda asing tersebut oleh karena adanya kontraksi uterus maka akan memberi gejala umum berupa nyeri perut karena kontraksi disertai perdarahan dan pengeluaran seluruh atau sebagian hasil konsepsi (Proverawati dan Wati, 2011).

Selain itu ada beberapa faktor predisposisi penyebab abortus diantaranya umur dan paritas. Dilihat dari paritas ibu yang mengalami anemia dan abortus banyak dialami oleh primipara, hal ini terjadi karena pengalaman ibu primipara masih sangat minim dengan tanda bahaya pada kehamilan muda, serta kebutuhan Fe dan nutrisi pada kehamilan muda. Dilihat dari usia ibu, usia ibu merupakan salah satu faktor risiko yang berhubungan dengan kualitas kehamilan. Usia yang paling aman atau biasa dikatakan waktu reproduksi sehat adalah antara umur 20 tahun sampai umur 30 tahun. Penyulit pada kehamilan remaja salah satunya abortus lebih tinggi dibandingkan waktu reproduksi sehat. Keadaaninidisebabkanbelummatangnyaalatrepro duksiuntukhamil,

sehinggadapatmerugikankesehatanibumaupunper kembangandanpertumbuhanjanin.

Menurut Manuaba (2013), kehamilan yang rawanterjadi pada kehamilan pertama dan risiko akan berkurang pada kehamilan kedua dan ketiga. Bahaya akan kembali meningkat saat kehamilan keempat dan berikutnya. Hasil Survey Kesehatan Rumah Tangga (SKRT) menunjukkan bahwa wanita dengan paritas lebih dari tiga mempunyai kecenderungan mengalami komplikasi dalam kehamilannya. Hal ini berkaitan dengan gangguan pada plasenta dan sirkulasi nutrisi ke janin yang terganggu. Sejalan dengan pendapat Cunningham (2013), faktor risiko bayi berat lahir rendah dibagi menjadi faktor risiko pada ibu, faktor risiko dalam kehamilan, faktor risiko pada janin dan faktor risiko lainnya yang belum diketahui. Anemia 
pada ibu hamil merupakan salah satu faktor resiko dari keluaran bayi yang tidak baik, berhubungan dengan kelahiran prematur, dan berat bayi lahir rendah.

Terdapat beberapa faktor yang dapat menyebabkan abortus diantaranya adalah faktor janin, faktor ibu, faktor bapak, faktor infeksi dan faktor nutrisi. Kekurangan gizi pada bumil dapat menyebabkan BBLR, terhambatnya pertumbuhan otak janin, bayi lahir dengan kurang darah (anemia), bayi mudah kena infeksi dan dapat mengakibatkan abortus. Masalah gizi yang sering terjadi pada ibu hamil adalah anemia defisiensi zat besi (Paath dkk, 2005).

Menurut Depkes RI (2009), anemia pada ibu hamil juga dapat berpengaruh terhadap lahirnya bayi BBLR. Hal tersebut terjadi karena kurangnya suplai oksigen dan asupan nutrisi pada plasenta yang akan berpengaruh pada fungsi plasenta terhadap pertumbuhan janin. Berdasarkan penelitian yang dilakukan oleh Sulistyorini (2011), tentang hubungan antara anemia dalam kehamilan dengan kejadian abortus di RSUD Sukoharjo mendapatkan hasil penelitian yaitu mayoritas kejadian abortus terjadi pada ibu hamil yang tidak mengalami anemia sebesar $62(68,1 \%)$ artinyabahwa tidak ada hubungan antara anemia dalam kehamilan dengan kejadian abortus.

Penelitian yang dilakukan oleh Altika (2015) tentang Hubungan Usia Ibu Hamil dan Anemia Dengan Kejadian Abortus Di RSUD Ambarawa menyimpulkan bahwa ada hubungan antara usia ibu hamil dan anemia dengan kejadian abortus, usia ibu hamil beresiko sebesar 3,489 kali terjadi abortus, dan anemia beresiko sebesar 4,533 kali terjadi abortus. Sejalan dengan penelitian Irayani (2015) yang menunjukkan terdapat hubungan secara statistik antara paritas ibu dengan kejadian abortus dengan OR: 3,048 artinya ibu dengan paritas berisiko (>4) memiliki risiko 3,048 kali lebih tinggi untuk mengalami abortus dibandingkan ibu dengan paritas yang tidak berisiko ( $<4$ anak).

Menurut pendapat peneliti kejadian anemia pada ibu hamil khususnya di Kota Palu disebabkan karena kurangnya daya konsumsi ibu hamil terhadap makanan yang dapat meningkatkan kadar $\mathrm{Hb}$ dan kepatuhan untuk mengkonsumsi tablet $\mathrm{Fe}$ yang masih sangat kurang. Hal ini menjadi faktor penyebab tingginya kasus anemia dan kejadian abortus di wilayah Kota Palu dan sekitarnya.

Kelemahan dalam penelitian ini adalah peneliti hanya menggunakan variabel tunggal yaitu anemia defisiensi besi dengan kejadian abortus. Sampel dalam penelitian hanya menggunakan sampel disalah satu rumah sakit, tanpa mencari kelompok pembanding dirumah sakit sekitar Kota Palu.

\section{SIMPULAN}

Berdasarkan hasil penelitian ditemukan bahwa ada hubungan antara antara anemia defisiensi besi pada ibu hamil dengan kejadian abortus di Nifas RSU Anutapura Palu.

\section{SARAN}

Penelitian ini menyarankan agar bidan semakin meningkatkan pemberian informasi melalui penyuluhan tentang anemia pada kehamilan, konsumsi makanan sehat dan seimbang dan meningkatkan konsumsi tablet $\mathrm{Fe}$ sehingga angka kejadian abortus pada ibu hamil menjadi menurun. Bagi peneliti selanjutnya dapat mengembangkan penelitian dengan jumlah variabel yang lebih banyak lagi seperti status sosial ekonomi, status gizi, riwayat penyakit.

\section{DAFTAR PUSTAKA}

Altika. 2015. Hubungan Usia Ibu Hamil Dan Anemia dengan Kejadian Abortus Di RSUD Ambarawa. http://www.usu.respiratory.co.id (Diakses pada 05 Februari 2016).

Cunningham. 2013. Obstetri Williams, Jakarta: EGC.

Depkes RI. 2009. Anemia dan Penanggulangannya. Depkes RI. Jakarta.

Dinas Kesehatan Kota Palu. 2015.Profil Dinas Kesehatan Kota Palu. Dinkes Kota Palu. Palu.
Dinas Kesehatan Provinsi Sulawesi Tengah. 2015. Profil Dinas Kesehatan Provinsi Sulawesi Tengah.Palu.

Manuaba, IBG. 2012. Ilmu Kebidanan, Penyakit Kandungan dan KB untuk Pendidikan Bidan Edisi 2, Jakarta: EGC.

Manuaba, IBG. 2013. Pengantar Kuliah Obstetri.Jakarta: EGC.

Paath, Erna, Francin. 2005. Gizi dalam Kesehatan Reproduksi. Jakarta: EGC.

Prawirohardjo. 2013. Ilmu Kebidanan. Yogyakarta: Yayasan Bina Pustaka. 
Proverawati dan Wati. 2011. Anemia dan Anemia Kehamilan. Yogyakarta: Nuha Medika.

Riskesdas. 2013. Riset Kesehatan Dasar. Kemenkes RI. Jakarta.

Rukiyah dan Yulianti. 2010. Asuhan Kebidanan I Kehamilan. Jakarta: Trans Info Media.

RSU Anutapura. 2014. Profil RSU Anutapura Palu. RSU Anutapura Palu.Palu

RSU Anutapura. 2015. Profil RSU Anutapura Palu. RSU Anutapura Palu.Palu.
RSUD Madani. 2015. Profil RSUD Madani. RSUD Madani. Palu

Soeprono. 2013. Pemberian Tablet Fe. Yogyakarta: Diva Prest.

Sulistyorini. 2011. Hubungan Antara Anemia Dalam Kehamilan Dengan Kejadian Abortus di RSUD Sukoharjo.http://www.usu.respirotory.ac.id (Diakses pada 20 Juni 2016). 